\title{
Estratégias para experiências significativas no ensino de criação publicitária
}

Rudinei Kopp

Doutor em Comunicação Social pela PUCRS e professor no Departamento de Comunicação Social da Universidade de Santa Cruz do Sul.

E-mail: rudinei_kopp@yahoo.com.br

Fábio Hansen

Doutor em Letras pela UFRGS, professor no Departamento de Comunicação Social da Universidade Federal do Paraná (UFPR) e professor permanente no Programa de Pós-Graduação em Comunicação da UFPR na linha de pesquisa Comunicação e Formações Socioculturais. E-mail: fabiohansen@yahoo.com

Resumo: Este artigo é uma fração da investigação longitudinal intitulada 0 ensino de criação publicitária, realizada pelo grupo de pesquisa Inovação no Ensino de Publicidade. Nele refletimos sobre outros modos de ensinar, tomando a sala de aula como campo de observação. Para tanto, analisamos uma experiência significativa na disciplina de Direção de Arte II da Universidade de Santa Cruz do Sul (Unisc): criação de embalagens e peças promocionais à Feira Pedagógica da Escola Família Agrícola de Santa Cruz do Sul (Efasc). O material foi produzido e disponibilizado durante a Semana dos Produtos Orgânicos da Efasc, em 2016. A situação acompanhada e monitorada se revelou significativa porque a ação criativa do professor, planejando cuidadosamente a atividade, gerou um exercício desafiador favorável à prática criativa. Igualmente, a criação de mecanismos de recompensa estimulou a inserção estudantil em práticas sociais, potencializando experiências vividas em outras situações de aprendizagem.
Abstract: This paper is part of a longitudinal study entitled Teaching Advertising Creation, which was carried out by the research group on Innovation in Advertising Teaching. This study approaches different forms of teaching by taking the classroom as the observation field. Therefore, this study analyzes a significant experience observed along the course of Art Direction II in the University of Santa Cruz do Sul (Unisc): creation of packaging and promotional pieces for the Pedagogical Fair in the Agricultural Family School of Santa Cruz do Sul (Efasc). The material was produced and became available during the Organic Products Week of EFASC in 2016. The situation was monitored, and it proved to be significant due to the creative action promoted by the professor, who carefully planned the activity and generated an appropriate challenging exercise for creative practice. Likewise, the reward mechanisms proposed have stimulated student insertion into social practices, enhancing experiences in other learning situations. 
Desse modo, o ensino baseado em projetos beneficiou a integração entre os conteúdos programáticos com problemas vivenciados por comunidades, trazendo sentido para a experiência de aprender criatividade.

Palavras-chave: publicidade; ensino; criatividade; trabalho docente; formação publicitária.
Accordingly, project-based teaching has benefited the integration between the class content and community issues, which brings meaning to the experience of learning creativity.

Keywords: advertising; teaching; creativity; educational work; advertising formation.

\section{INTRODUÇÃO: O ENSINO DE CRIAÇÃO PUBLICITÁRIA BASEADO EM PROJETO}

Os cursos superiores em publicidade produzem, anualmente, um expressivo número de graduados, em sua maioria treinados para aplicar o já conhecido de maneira convencional ${ }^{1}$. Soma-se a isso o fato de reproduzirem os modelos criativos do mundo do trabalho publicitário, com aulas de criação seguindo o padrão de qualquer outra disciplina.

Piratininga, em sua trajetória como docente, deparou recorrentemente com discentes que fechavam seu espírito para voos mais arrojados, agarrando-se às regras consagradas. Os jovens "procuram no velho não apenas o exemplo, mas a fórmula e a receita testada, abrindo mão de seu mais precioso potencial: o atrevimento, a impetuosidade, a inovação"2.

Parece-nos desafiador refletir sobre os níveis de estímulos promovidos pelo professor para o desenvolvimento do pensamento, da ideia e da criatividade a fim de fazer que os estudantes expressem seu potencial além dos métodos reprodutivos. Cabe ao professor repensar as estratégias de ensino para contagiá-los e excitá-los em diferentes direções em detrimento a enquadrá-los em um contexto estritamente mercadológico.

Uma das estratégias para experiências significativas no processo de ensino-aprendizagem está alicerçado em projetos ${ }^{3}$, envolvendo atividades desafiadoras capazes de colaborar para a criatividade estudantil ao oportunizar a vivência de outras experiências e, por extensão, a excitação do saber criativo. Sternberg e Lubart ${ }^{4}$ salientam que a criatividade é a capacidade de criar algo diferente, que seja útil ao indivíduo ou à sociedade, direcionando o esforço criativo para a resolução de problemas do dia a dia.

É o que verificamos, ao longo do primeiro semestre de 2016, no projeto de criação de embalagens e peças promocionais realizado na disciplina de Direção de Arte II (doravante DA) do curso de Publicidade e Propaganda da Universidade de Santa Cruz do Sul (Unisc) para a Feira Pedagógica da Escola Família Agrícola de Santa Cruz do Sul (Efasc). Essa experiência é parte da investigação longitudinal do Grupo de Pesquisa Inovação no Ensino de Publicidade ${ }^{5}$.

1. ALENCAR, Eunice M L. Soriano de; FLEITH Denise de Souza. Inventário de práticas docentes que favorecem a criatividade no Ensino Superior. Psicologia: Reflexão e Crítica v. 17, n. 1, p. 105-110, 2004.

2. PIRATININGA, Luiz Celso de. Publicidade: arte ou artifício. São Paulo: T.A. Queiroz, 1994, p. 33

3. ANASTASIOU, Léa. Ensinar, aprender, apreender e processos de ensinagem. In: ANASTASIOU Léa; ALVES, Leonir (org.) Processos de ensinagem na universidade: pressupostos para as estratégias de trabalho em aula. Joinville: Univille, 2006.

4. STENBERG, Robert LUBART, Todd. The concept of creativity: prospects and paradigms. In: STERNBERG, Robert: LUBART Todd (org.). Handbook of creativity. Londres: Cambridge University Press, 1999.

5. Disponível em: https:// www.grupoiep.com/. 


\section{comunicação \& educação • Ano XXV • número 1 • jan/jun 2020}

Temos por objetivo identificar estratégias para experiências significativas no ensino de criação publicitária, reconhecendo nelas inovações nas práticas docentes adaptáveis às condições atuais do ensino superior de publicidade.

Analisar criticamente o processo de ensino de criação publicitária exige partir de concepções teóricas provenientes de outros campos do saber. É o caso da aproximação dos preceitos de Santrock ${ }^{6}$, Sternberg e Lubart ${ }^{7}$ - instituição de mecanismos de recompensa, de desafios e de níveis evolutivos de complexidade no processo criativo - da noção de ecossistema comunicativo de Martín-Barbero ${ }^{8}$ - ampliar o ambiente de aprendizagem, propiciando espaços experimentais de produção de conhecimento, como é a experiência de ensino com extensão aplicada a um projeto comunitário local na perspectiva de formação do publicitário cidadão.

No projeto Unisc-Efasc definiu-se como objeto de trabalho de DA a Feira Pedagógica da Efasc - parte de uma de rede de escolas em todo o Brasil que tem por metas a produção de alimentos orgânicos e o estímulo à permanência do jovem no campo como perspectiva economicamente viável. Os estudantes da Efasc mantêm-se completamente integrados às suas origens. Eles vêm do campo, e suas famílias seguem produzindo para comercialização e subsistência. A Efasc realiza desde 2013 uma feira e oferece, às segundas-feiras, no saguão da escola, alimentos orgânicos produzidos pelos alunos em suas propriedades. As definições de valores, o atendimento aos consumidores e a divulgação ficam a cargo dos próprios estudantes.

Este projeto articulou os conteúdos ministrados em aula na disciplina de DA com as necessidades da feira da escola: peças promocionais, sinalização e material para ponto de venda. Considerando as possibilidades de execução das peças, definiu-se pela criação de etiquetas de identificação em três tamanhos, peça promocional para o PDV (banner ou faixa), placa de rua indicativa à feira, peça promocional de baixo custo e imagens de divulgação para redes sociais.

Houve cuidado em realizar uma atividade ao alcance da capacidade dos estudantes do quinto período do curso de Publicidade da Unisc e aderente ao conteúdo programático e às características da disciplina de DA. Por outro lado, a extensão do conhecimento criativo extrapolou a variedade de domínios técnicos que as disciplinas de criação sugerem em sua rotina, potencializando tanto o profissional quanto o humano. Humanizar os futuros profissionais

6. SANTROCK, John. Psicologia educacional. Porto Alegre: AMGH, 2009.

7. STENBERG; LUBART, op. cit.

8. MARTÍN-BARBERO Jesús. A comunicação na educação. São Paulo: Contexto. 2014.

9. Ibidem. talvez seja o que mais importa. As barreiras que o sujeito impõe não raro nos soam como limitadores maiores do desenvolvimento da capacidade criativa do que o processo. Nesse sentido, o fator humano é uma variável cultural chave ao desempenho criativo.

Ao envolver o seu entorno, o projeto Unisc-Efasc nos conduz à mobilização da noção de ecossistema comunicativo de Martín-Barbero ${ }^{9}$ : o conhecimento se torna significativo quando as estratégias de ensino aproximam o cotidiano universitário do entorno, estabelecendo relações substantivas, promovendo 
motivações sociais, gerando valores positivos para os discentes e o mundo que os cerca. Para Martín-Barbero, o ecossistema comunicativo é constituído pela mistura de linguagens e saberes que vão além dos livros e da escola. Seria insensato isolar docentes e discentes de outros contextos educacionais. Isso leva ao risco de distanciar o processo de ensino-aprendizagem daquilo que ocorre na vida cotidiana. É o próprio Martín-Barbero quem conta que a escola ainda exige do sujeito da aprendizagem que não leve a sensibilidade para a sala de aula, porque as emoções estudantis "desestabilizam a autoridade dos professores. Daí que o mundo onde o sujeito jovem habita seja menos o da escola"10.

Historicamente, as instituições de ensino escolar fundaram suas bases na lógica da hierarquia e da racionalização em detrimento das emoções. Essa constatação deriva da percepção de Martín-Barbero de que "a escola continua consagrando uma linguagem retórica e distante da vida" 1 . A principal mudança que acontece na educação é que a aula conta cada vez menos do que o entorno. Significa cambiar as estratégias de ensino, potencializando as experiências vividas em outras situações de aprendizagem. Ato contínuo, não há como afastar o aprendizado das ruas, dos locais urbanos e/ou rurais, das interações sociais.

A Feira Pedagógica da Escola Família Agrícola foi adotada para aproximar o cotidiano da sala de aula ao mundo contemporâneo. Sair da rotina da sala de aula, interagir com a sociedade e entrar em contato com outra realidade - de uma escola agrícola, de jovens rurais, de produção e comércio de alimentos orgânicos e seus consumidores - é reconhecer que o ensino hoje está pautado na pluralidade e na diversidade do pensamento; em trocas simbólicas que transcendem o espaço da sala de aula. Orozco Gómez ${ }^{12}$ argumenta que se aprende de muitas maneiras, e que a escola não é o único lugar onde se produz aprendizagem, pois emerge nos estudantes "um potencial de saberes diversos mas entrelaçados, que provêm menos do saber escolar que de sua experiência cultural"13. Estamos acompanhando um momento rico e complexo de mutações em que "o saber escapa dos lugares sagrados" 14 para se tornar disperso e fragmentado, escapando ao modelo linear e sequencial para, assim, desenvolver novas modalidades de aprendizagem formais e não formais.

\section{DESAFIOS E RECOMPENSAS PARA EXPERIÊNCIAS SIGNIFICATIVAS}

Pesquisa desenvolvida por Chambers ${ }^{15}$ constatou que professores universitários preocupados com o aprimoramento da criatividade nos estudantes apresentam perfis que envolvem o entusiasmo e o encorajamento da independência estudantil, estimulando a iniciativa dos estudantes e escutando com atenção as suas intervenções. De fato, preocupar-se apenas com o conteúdo informativo, utilizar formas de avaliação que exigem apenas a reprodução do conteúdo
10. Idem, p. 31.

11. Idem, p. 25

12. OROZCO GÓMEZ Guillermo. Educomunicação: recepção midiática, aprendizagens e cidadania. São Paulo: Paulinas, 2014.

13. MARTÍN-BARBERO, op. cit., p. 126.

14. Ibidem

15. CHAMBERS, Jonathan College teachers: their effect on creativity of students. Journal of Educational Psychology, v. 65 n. 3, p. 326-334, 1973. 
dado em classe e adotar sempre a mesma metodologia de ensino são condições desfavoráveis à produção de um discurso criativo em aula.

Trabalhar com desafios e com projetos reais revelou-se um caminho significativo no ensino de criação publicitária. Nesse sentido, a ação educativa de projetos diz respeito ao modelo de estratégia de ensino que pode dar vazão à imaginação. Igualmente, impõe desafios que podem promover a geração de ideias criativas e incentivar os discentes a pensar ideias novas relacionadas ao conteúdo das disciplinas.

As estratégias promovidas na disciplina de DA envolveram os estudantes numa dimensão de desafios, conforme sugere Santrock ${ }^{16}$. O primeiro conteúdo foi relacionado ao desenvolvimento de embalagens: funções, mercado, confecção de planta técnica e aplicação de fundamentos de design. Foi proposto como atividade inicial um chá orgânico. Os estudantes pesquisaram sobre o cultivo e a comercialização de produtos orgânicos para, em seguida, materializar esse conteúdo em texto promocional no verso da caixa de chá. O propósito era prepará-los já nas três primeiras semanas de aula para o projeto final, gradualmente elevando a complexidade dos exercícios.

O propósito da disciplina de DA estava em gerar um desafio, lançado a partir de microproblemas programados em níveis evolutivos de dificuldade. Ao final da terceira semana de aula os estudantes foram informados sobre a visita do cliente (Efasc) na semana seguinte. O professor instruiu os aprendizes para dedicarem especial atenção à percepção de problemas que a instituição poderia ter em relação às formas de comercialização e comunicação dos produtos da Feira Pedagógica.

O primeiro contato entre o cliente (Efasc) e os alunos da Unisc aconteceu na quarta aula do semestre. Uma aluna e um aluno do terceiro ano da escola, acompanhados de um professor, estiveram na Unisc e compartilharam dados sobre a história, a metodologia da escola e o perfil dos estudantes; mostraram imagens relacionadas à Feira Pedagógica; contextualizaram as condições nas quais ela costumava ser realizada. Na sequência, instaurou-se o diálogo para detectar se havia ou não problemas de comunicação na feira. Após o encerramento das atividades com os integrantes da Efasc, a turma de DA sistematizou coletivamente as percepções.

Cabe destacar o ambiente colaborativo como dimensão-chave para dar voz aos estudantes, encorajando-os a ter iniciativa para se expressar e exercer atitude crítica e construtiva. A partir do processo colaborativo diagnosticaram-se: ausência de identidade e padronização visual; materiais publicitários com aparência amadora; inexistência de peças informativas facilitadoras da comercialização; e fragilidade no material de comunicação empregado em redes sociais. Havia também potencialidades: preços baixos para produtos de ótima procedência; imagem positiva da Efasc na cidade; domínio sobre o que era produzido; e a feira como oportunidade de contato entre consumidores, produtores e escola. 
Ficou acordado entre professor e estudantes que a semana de intervalo até a aula seguinte seria dedicada a pesquisas sobre a produção orgânica em pequenas propriedades e sobre a realidade do jovem do campo; e investigar características das feiras municipais - vistas como potencial concorrência - e também características sobre o consumidor local, nacional e global de orgânicos.

Configurou-se, assim, uma série de atividades criativas em níveis evolutivos de complexidade para o estudante se aventurar em práticas desafiadoras progressivamente. É o que defende Santrock ${ }^{17}$, para quem o desenvolvimento da capacidade criativa depende de como o docente programa o conjunto de atividades, considerando que a "criatividade é um fenômeno complexo e plurideterminado" 18 .

A complexidade da tarefa, capaz de provocar desafios, foi denominada pelo docente de DA "mundo possível" e "mundo ideal". No primeiro, o propósito era apresentar peças publicitárias que poderiam ser empregadas de fato, respeitando as restrições orçamentárias da escola. O "mundo ideal" era uma segunda proposta que ampliava a primeira, trabalhando com ideias de médio e longo prazo, sem restrição orçamentária. A indicação era que os dois "mundos" mantivessem uma identidade visual em comum. As duas propostas foram encaminhadas à Efasc, deixando claro que a primeira ideia era exequível e a segunda era um ensaio criativo estimulando uma visão de projeto para o futuro da Feira Pedagógica.

Outra variável considerada é a criação de mecanismos de recompensa para superar os desafios impostos ao longo de processo de criação, promovendo estímulos que favorecem a prática criativa. No ensino superior a recompensa pode ser de ordem objetiva e/ou subjetiva: chegar a um conhecimento parecido ao do professor, com o intuito de interpelá-lo; mostrar à turma que sabe, com o intuito de reconhecimento dos pares e do professor; conquistar a nota máxima; ter seu trabalho selecionado para veiculação; determinada premiação atribuída pelo professor, entre tantas outras de ordem íntima, como o sentimento de autorrealização pelo próprio aprendizado.

As etapas referentes ao projeto desenvolvido mereciam uma gratificação para sustentar o engajamento dos estudantes do início ao fim. Além de ter a proposta selecionada e o material produzido, o grupo vencedor de alunos da Unisc foi até a Efasc apresentá-la aos alunos e professores (Figura 1). O lançamento do novo material ocorreu num evento durante a Semana dos Produtos Orgânicos da Efasc, na décima semana do semestre. No evento, que recebeu cobertura da mídia do município de Santa Cruz do Sul, os estudantes da Unisc apresentaram a comunicação publicitária criada no projeto. $\mathrm{O}$ material vem sendo usado desde então pela Efasc

O material apresentado, aprovado, finalizado e considerado como aplicável - "mundo possível" - foi constituído por: marca/identidade visual (Figura 2), sistema de placas/banners de identificação aplicado a uma versão para o acesso à Efasc (Figura 3), etiquetas de identificação para produtos (Figura 4), peça promocional livre e de baixo custo para divulgação da Feira Pedagógica (Figura 5), faixa de identificação para PDV (Figura 6) e imagens para divulgação em redes sociais (Figura 7). 
comunicação \& educação • Ano XXV • número 1 • jan/jun 2020

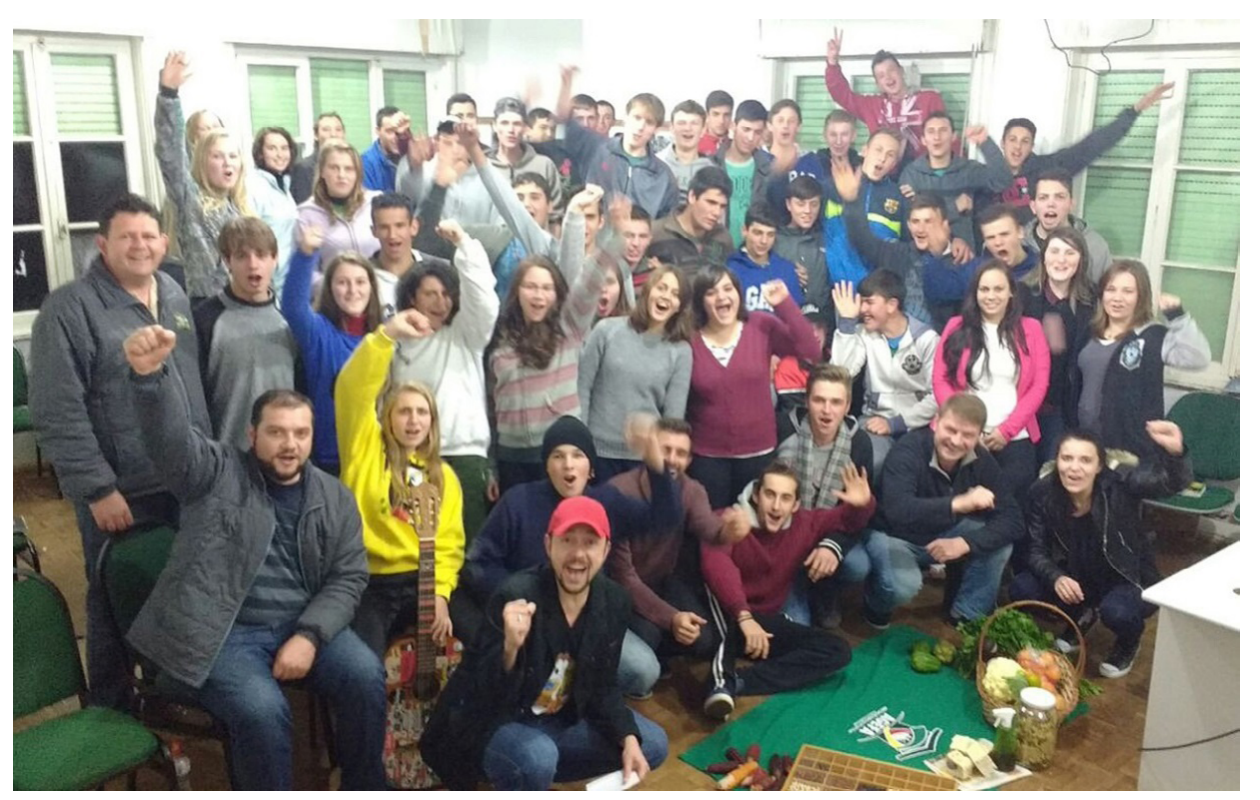

Figura 1: Dia da apresentação das propostas desenvolvidas pelos estudantes da Unisc para professores e estudantes da Efasc.
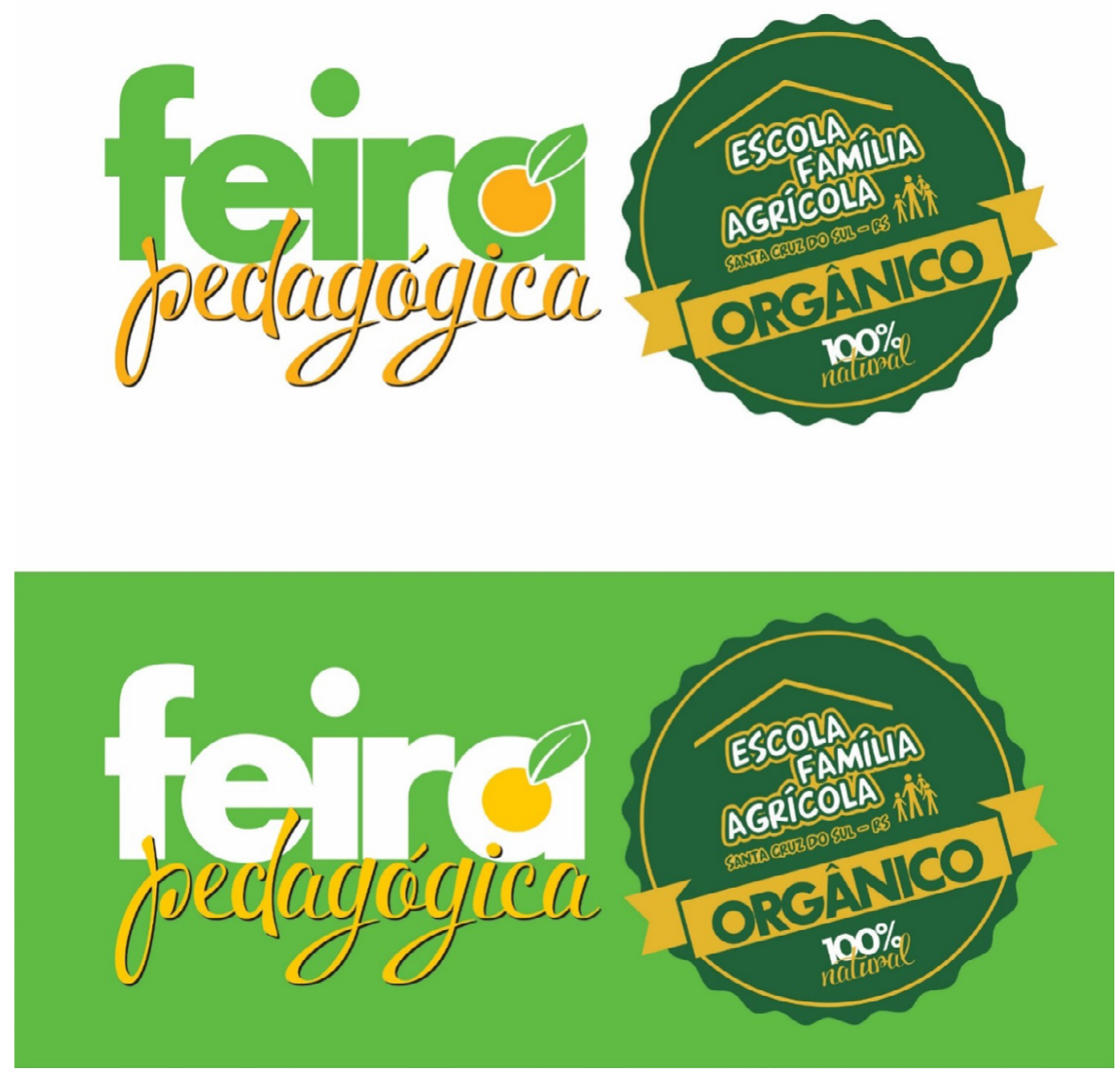

Figura 2: Marca aprovada para identificar a Feira Pedagógica da Efasc 
Estratégias para experiências significativas no ensino de criação publicitária

- Rudinei Kopp e Fábio Hansen

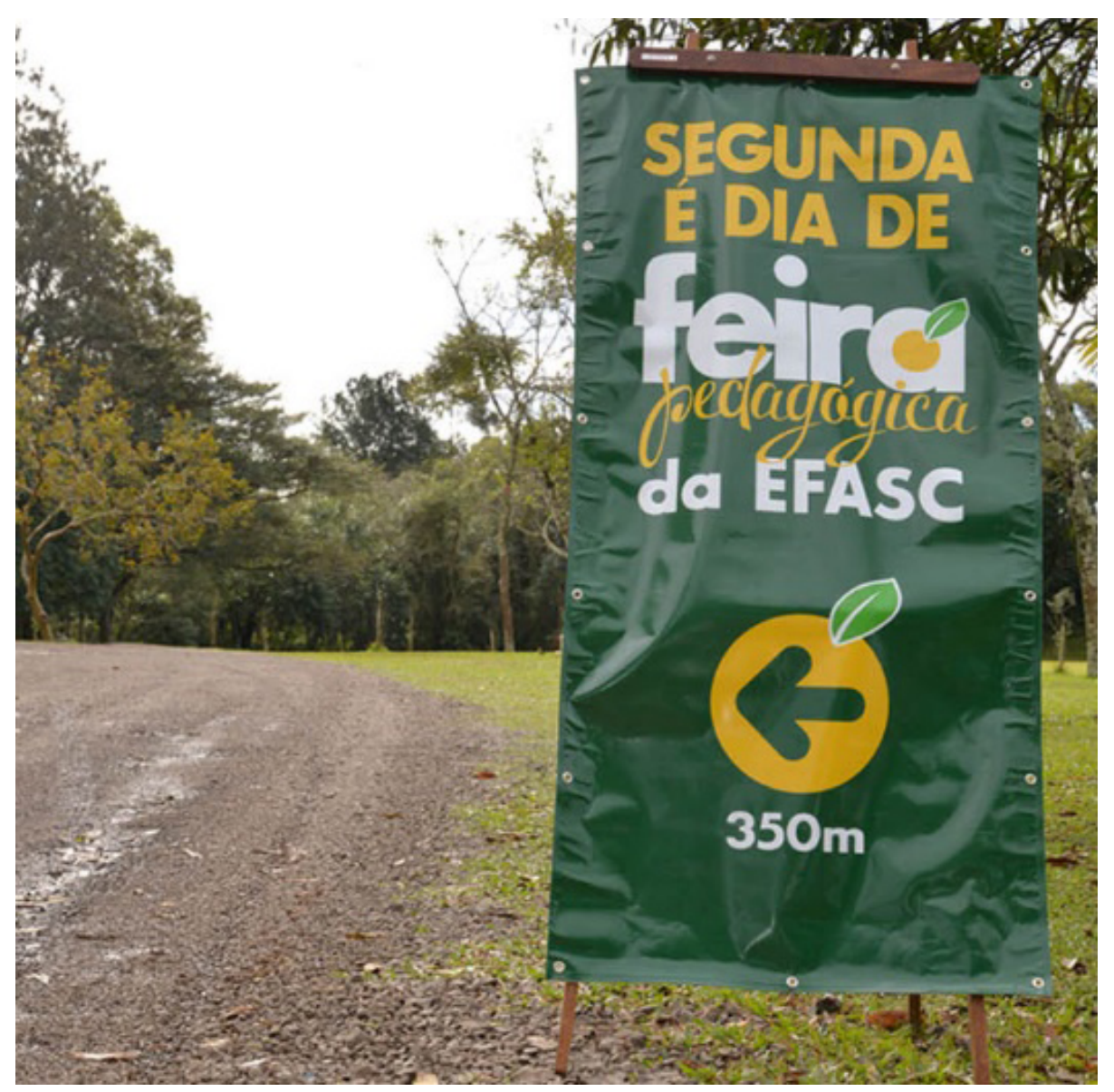

Figura 3: Placa indicativa de rua com aplicação da marca, dia da semana e distância

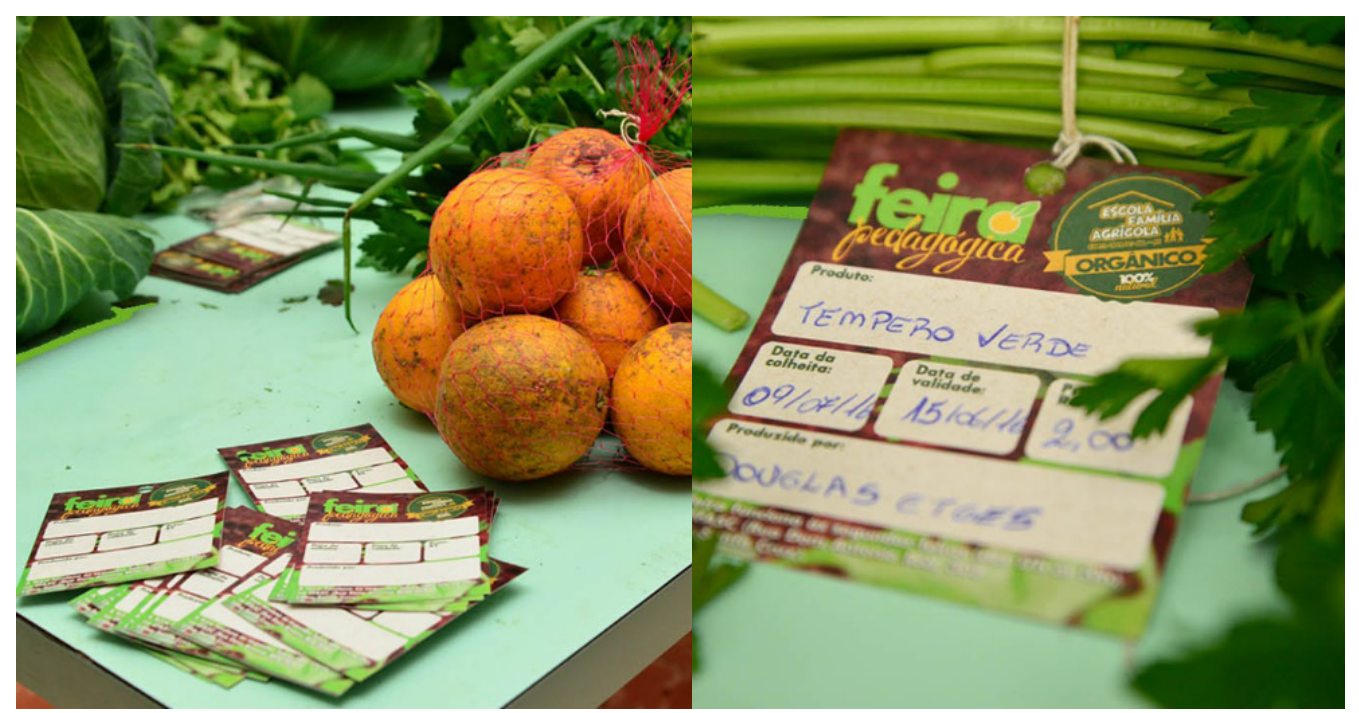

Figura 4: Etiquetas em papel reciclável com identificação de produto, data de produção, data de validade, preço e estudante produtor 
comunicação \& educação • Ano XXV • número 1 • jan/jun 2020

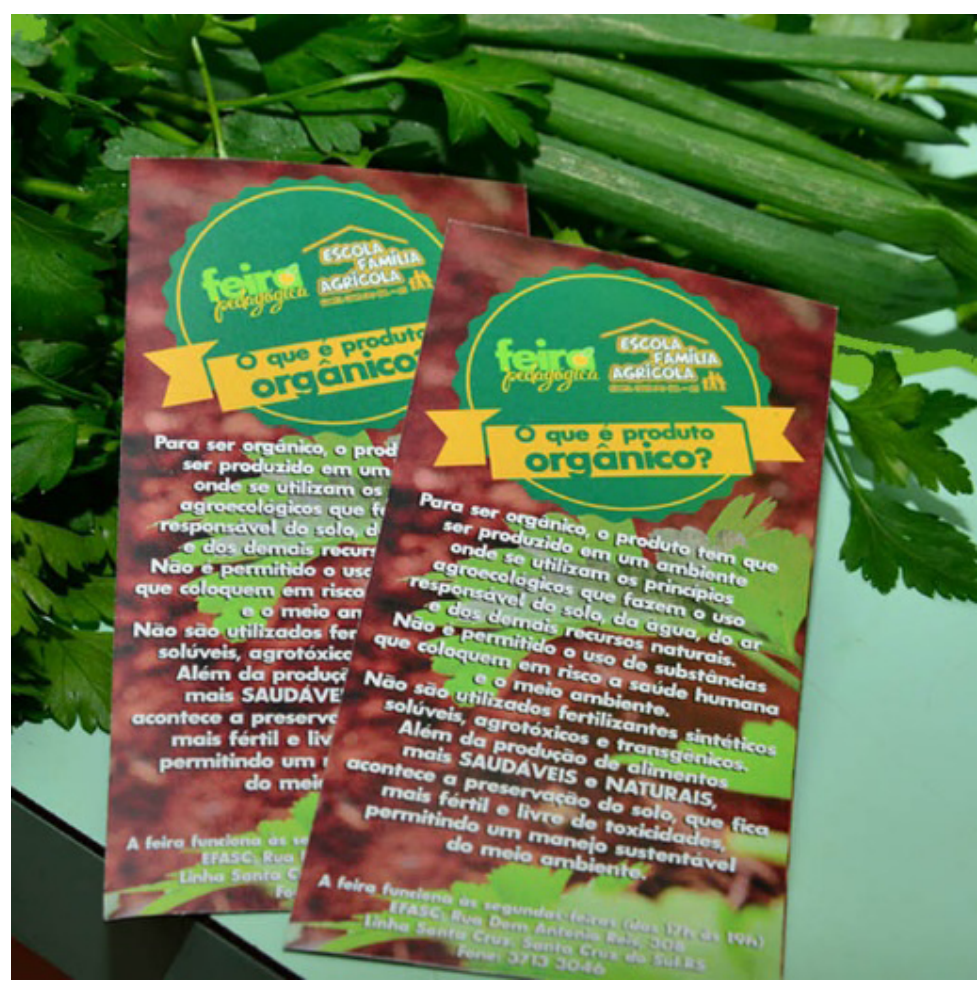

Figura 5: Material promocional com texto explicativo sobre produtos orgânicos. A peça também informa a data e o endereço da Feira Pedagógica

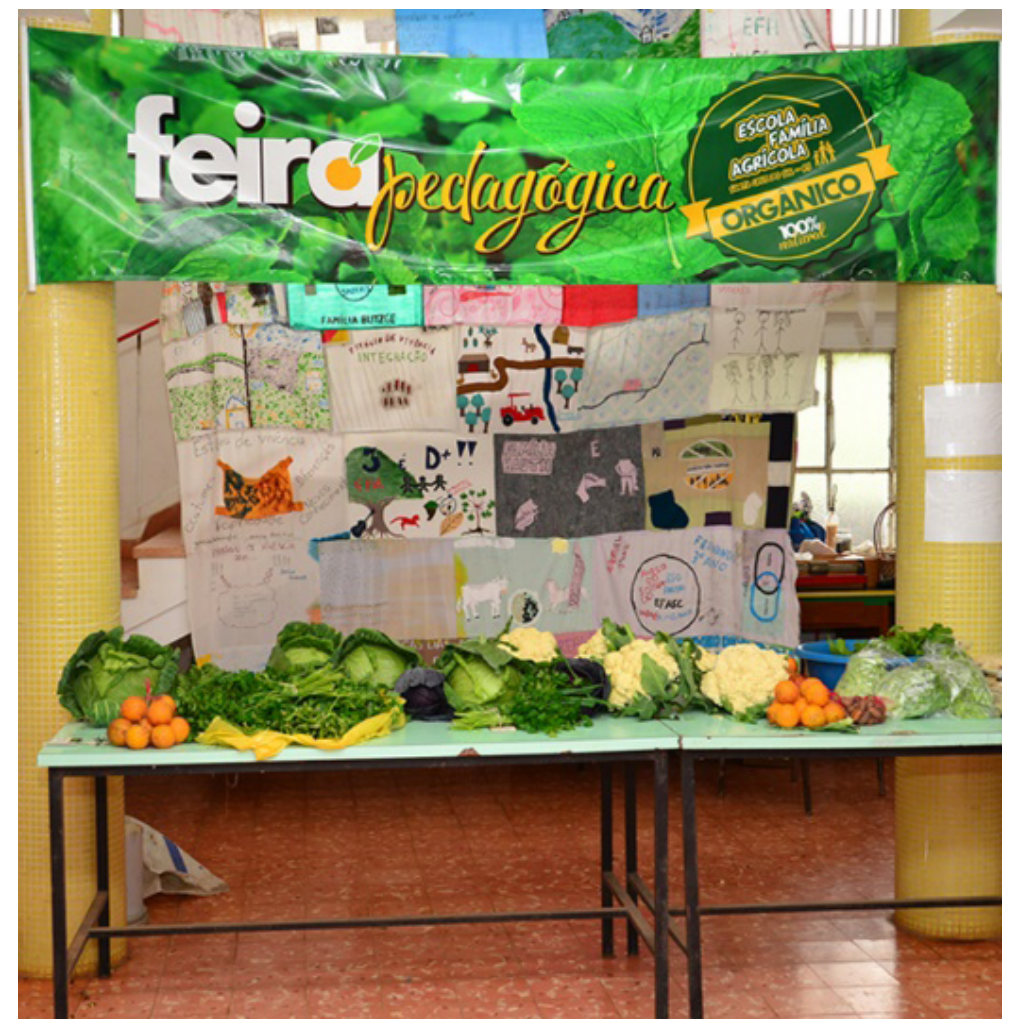

Figura 6: Faixa de identificação interna (saguão da Efasc) para a Feira Pedagógica 


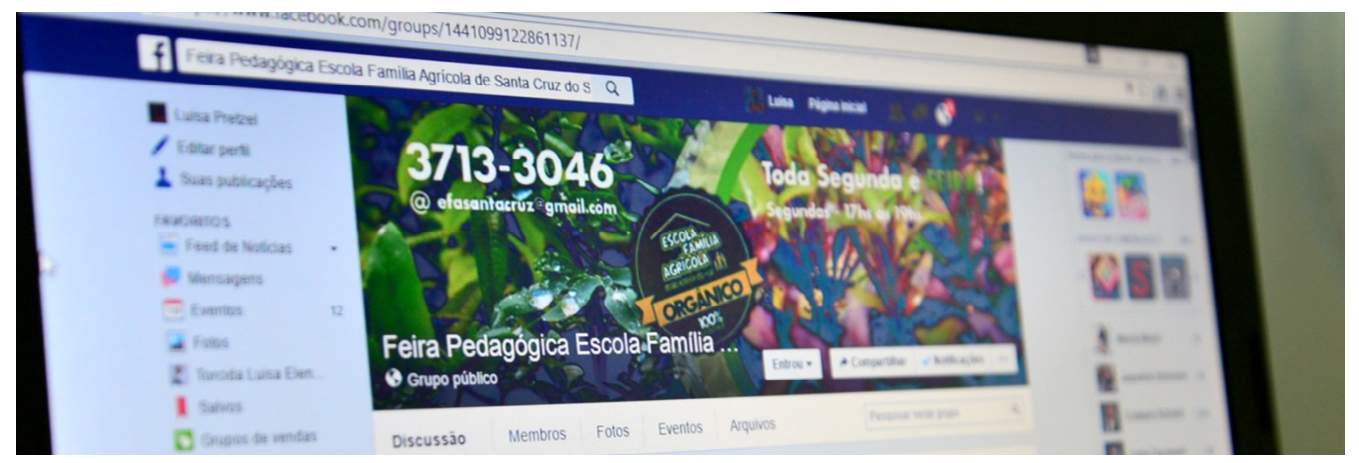

Figura 7: Identidade para capa de Facebook

O reconhecimento, a visibilidade proporcionada pela mídia, a confecção e a circulação do material são premissas de engajamento e estímulo à criatividade - que pressupõe envolver e motivar para o desenvolvimento de ideias a partir do conhecimento e da experiência pessoal. Premiar a criatividade estudantil se mostra uma experiência produtiva, pois nossos jovens são "educados para a atitude conformista e homogênea a que os sistemas escolares os condenam" 19 .

Aos estudantes não premiados cabe a tarefa de compreender que "se aprende de muitas maneiras: pela descoberta, pela tentativa e pelo erro" ${ }^{20}$, desde que os erros sejam encarados como uma etapa para a conquista da excelência, com uma postura rumo à maturidade, pela qual os professores são responsáveis não habituando os alunos somente ao sucesso, mas os preparando para lidar com a imprevisibilidade, com o risco, com opiniões e avaliações contrárias - fundamentais à formação do conhecimento.

\section{PLANEJAMENTO DE AULAS CRIATIVAS E ORIENTAÇÃO DE ESTUDANTES CRIATIVOS}

O trabalho docente é uma tarefa de planejamento criativo. Há um conjunto de fatores que se deve priorizar na formação de uma consciência criativa (e menos reprodutiva): o modo como se planejam as aulas e se ministram os conteúdos, como se concebem as avaliações, como se divide a turma em equipes e se estabelece o número de integrantes; a ponderação sobre os conhecimentos prévios advindos de disciplinas anteriores; a adaptação dos conteúdos diante do cenário projetado, alinhando as atividades ao anunciante prospectado; a flexibilização das aulas às intercorrências; e a concessão de espaço a dúvidas que envolvam a construção do conhecimento.

No projeto estudado, o planejamento começou cedo. Um mês antes de iniciar o semestre letivo, o professor alinhavou a execução do projeto em parceria com a Efasc. Contatou a coordenação da escola, realizou reuniões e visitas para conhecer o perfil, os alunos, a metodologia de ensino, as condições de funcionamento e a filosofia da instituição. Os encontros se revelaram essenciais para, juntos - direção da escola e professor da disciplina de DA -,

19. CASTANHO, Maria Eugênia. A criatividade na sala de aula universitária. In: VEIGA, IIma; CASTANHO, Maria Eugênia (org.). Pedagogia universitária: a aula em foco. São Paulo: Papirus, 2000, p. 77

20. OROZCO GÓMEZ, op. cit., p. 25 
identificarem uma situação/objeto que poderia ser adotada como motivo para o trabalho em sala de aula. A Feira Pedagógica se adequava às condições que gerariam um briefing executável na equação tempo, conhecimentos técnicos e teóricos, e disponibilidade financeira para a produção.

Assim, ingressou-se no semestre com o planejamento do projeto consolidado, vislumbrando o aprender ativamente com problemas reais, desafios relevantes, atividades de pesquisa e combinação de tempos individuais e coletivos. O planejamento exigiu antecedência nos prazos entre as etapas do trabalho interno do professor: lançar ideias, traçar objetivos, identificar questões norteadoras, definir tarefas para dividi-las, criar cronograma e sincronizar agendas entre alunos e professores da escola e da universidade para as atividades conjugadas.

Essas fases de pensamento são momentos de decisão, crítica e imaginação. Exigem criatividade e doses de inventividade do professor publicitário, à medida que uma aula de práticas criativas demanda uma postura pedagógica compatível. Como publicitários de formação - professores sem licenciatura -, podemos nos valer da promoção de ações criativas, guiando-nos pela lógica de que somos professores de criação. Logo, devemos proporcionar aos estudantes exercícios criativos, antes de exigir que sejam criativos.

Ao observar o professor de criação, em tese examinaríamos estratégias de ensino de um sujeito criativo. $\mathrm{O}$ docente, quando se envolve com a atividade de ensinar criatividade, passa a ser avaliado pelos estudantes como um profissional criativo, que além da disciplina assegura criatividade em seus métodos. A docência é uma "profissão que dependerá dos saberes da área que já trazemos, mas também dos saberes próprios à profissão de professor”"1.

A ação criativa do professor "demanda habilidades comunicativas que lhe permitam criar um espaço comunicativo que se constitua no espaço onde as atividades podem fazer sentido para o desenvolvimento da criatividade"22. Tal espaço comunicativo se materializa em uma situação de aprendizagem em específico: a orientação - estratégia de ensino em que o professor acompanha os estudantes de forma sistemática e colabora na superação de dificuldades. No processo de orientação, por meio da sua presença como agente mediador, o professor desperta a capacidade de produzir angústias e questionamentos, cumprindo seu papel de propositor. A tarefa de quem ensina não é repassar ao

21. ANASTASIOU, Léa. Construindo a docência no ensino superior. In: ROSA Dalva; SOUZA, Vanilton (org.). Didática e práticas de ensino. Rio de Janeiro: DP\&A, 2002, p. 175.

22. MITJÁNS MARTÍNEZ, Albertina. A criatividade na escola: três direções de trabalho. Linhas Críticas, Brasília, v. 8, n. 15, p. 189-206, 2002, p. 32. seu interlocutor aquilo que já está assimilado, mas desafiá-lo e provocá-lo a (re) construir e negociar significados sobre determinados fatos, além da apropriação de conteúdos novos, antes desconhecidos e sobre os quais se pode avançar.

Nas aulas de DA observamos a divisão dos estudantes em equipes de trabalho. Na turma havia 26 estudantes divididos em onze equipes, formadas por no mínimo dois e no máximo três integrantes. A formação de grupos pequenos favoreceu a promoção de um ambiente colaborativo que ampliou a capacidade criativa dada à troca de conhecimentos heterogêneos, sem preterir a singularidade dos integrantes. O real monitoramento do professor, uma vez 
que os trabalhos foram orientados durante várias aulas, permitiu aos estudantes a aplicação de conteúdos de DA.

Antes das primeiras tentativas de construção dos layouts, foi possível acompanhar como cada grupo elencou os problemas e soluções imaginadas. Apenas depois dessa orientação o trabalho prosseguiu. Outra situação destacada foi a percepção dos rumos que as tarefas tomavam: o acompanhamento da rotina em aula fez o professor conhecer as particularidades de aprendizado dos estudantes e sentir a necessidade de acrescentar conteúdos relacionados a design gráfico. Fundamentos propostos por Lupton e Phillips ${ }^{23}$ foram incorporados para incrementar as atividades e estimular versões diferenciadas antes da definição da ideia final de cada grupo.

No trabalho de campo na Unisc identificamos um professor mentor, guia e orientador do estudante ao longo do seu desenvolvimento, sem se limitar ao papel exclusivo de transmitir conteúdo. A rotina em aula demonstrou a importância do trato do professor com os estudantes; a interação a fim de torná-lo conhecedor das particularidades de aprendizado deles, acompanhando de perto a evolução. O processo de orientação aproximou docente e discentes e permitiu ao professor envolvê-los para trabalhar em parceria, discutindo ideias e gerando desafios a serem resolvidos em conjunto.

Portanto, aulas planejadas "de modo a prover situações que os alunos devem resolver colaborativamente, em pequenos grupos" ${ }^{24}$, tendem a efetivar o diálogo de modo intenso no ato comum do conhecimento. O diálogo em grupo, especialmente nas circunstâncias de equipes menores, possibilita uma articulação mútua de escuta e fala, permitindo a exposição de opiniões contrárias tão importantes para a formação do conhecimento. Na perspectiva dialógica, a comunicação é circular. A educação, por meio do processo de ensino, não está no professor, na universidade ou no estudante. É nas relações e na reciprocidade da convivência entre sujeitos e conhecimento que ela se constitui. Como expressão desta densa relação entre os dois campos - comunicação e educação -, Martín-Barbero ${ }^{25}$ recorda da contribuição de Paulo Freire: "a porta para a comunicação que nos abre Paulo Freire é basicamente para a sua estrutura dialógica. Pois há comunicação quando a linguagem dá forma à conflituosa experiência do conviver, quando se constitui em horizonte de reciprocidade" da interlocução.

Nesse sentido, frisamos que o processo de orientação é uma estratégia para experiências significativas no ensino de criação publicitária, desde que prevaleça a abertura criativa. $\mathrm{O}$ acompanhamento do professor durante as atividades pode desenvolver uma tensão criativa, uma espécie de "adrenalina” para encorajar os discentes a experimentar, arriscar e vivenciar o que está sendo aprendido. No ponto de vista de Sodrée ${ }^{6}$, seria desenvolver a vivacidade, a capacidade de improvisação, de cooperação, com abertura para interatividade, inventividade e criatividade.
23. LUPTON, Ellen; PHILLIPS, Jennifer. Novos fundamentos do design. São Paulo: Cosac Naify, 2008.

24. MOREIRA, Marco Antonio. Abandono da narrativa, ensino centrado no aluno e aprender a aprender criticamente. In: VI ENCONTRO INTERNACIONAL E III EN CONTRO NACIONALDE APRENDIZAGEM SIGNIFICATIVA. Anais... São Paulo, 2010, p. 7.

25. MARTÍN-BARBERO, op. cit., p. 29.

26. SODRÉ, Muniz. Reinventando a educação: diversidade, descolonização e redes. Petrópolis: Vozes, 2012. 


\section{CONSIDERAÇÕES FINAIS}

As práticas docentes examinadas até aqui podem, dependendo da angulação, não ser encaradas como experiências significativas do ensino de criação publicitária. Então precisamos acrescentar, de imediato, o nosso raciocínio nuclear. Embora as práticas acompanhadas nas aulas de DA - cliente real, processo de orientação, formação de equipes de trabalho, resolução de problemas de comunicação publicitária expostos em um briefing de trabalho social - configurem ações institucionalizadas no cotidiano do ensino de criação publicitária, elas são incrementadas com toques pontuais de inovação. Ao valorizar o entorno na dinâmica de projetos, propor exercícios desafiadores com níveis evolutivos de complexidade e mecanismos de recompensa configura um conjunto de atividades criativas planejadas.

Ainda que ressoem procedimentos convencionais, apresentam uma condição diferenciada de utilização para elementos já existentes. Valorizamos as mínimas atitudes e comportamentos para a inserção da criatividade no contexto educacional. Logo, pequenas iniciativas factíveis, como os estímulos até agora examinados para gerar ações criativas em aula, são mudanças que impactam no ensino de criação e contribuem na formação do publicitário. Não defendemos que o professor abra mão de práticas consolidadas e modifique por completo todas as suas aulas, pois sabemos das dificuldades de rupturas muito bruscas.

Embora o processo de ensino-aprendizagem seja um modo culturalizado e social, é também um processo próprio a cada sujeito docente e discente, repleto de componentes, pois "cada um tem o seu modo próprio de organizar as aulas, de se movimentar na sala, de se dirigir aos alunos, de utilizar os meios pedagógicos, um modo que constitui uma espécie de segunda pele profissional"

O projeto Unisc-Efasc seria o contrabalanço do "mundo real" e do "mundo ideal", sem ignorar um, tampouco o outro, manifestando continuidades e descontinuidades com o modelo tradicional de ensinar publicidade. As disciplinas que implicam práticas criativas se organizam a partir de pequenos rompimentos, pois o processo criativo está sempre alternando entre a ordem e o caos, o conforto e o desconforto ${ }^{28}$.

De fato, importa o docente mostrar disposição para desestabilizar a estrutura do campo e provocar rupturas pontuais no microcosmo da sala de aula de criação publicitária. Rodari ${ }^{29}$ observava, já em 1982, a transformação do professor em um "promotor da criatividade. Não é mais ele que transmite um saber pronto". Exprime "o melhor de si mesmo, a desenvolver em si mesmo os hábitos da criação, da imaginação, do empenho construtivo em uma série de atividades". Os estudantes deveriam ser encorajados a explorar as possibilidades de subversão dos formatos existentes, recebendo dos professores suporte para expressar a criatividade, justamente o que acompanhamos no projeto Unisc-Efasc. 
De tudo que foi referido, importa-nos construir experiências que aliem o trabalho em aula com desafios aos estudantes; propor um conjunto de atividades criativas programadas em níveis evolutivos de complexidade; incentivar o estudante a pensar em novas ideias relacionadas ao conteúdo das disciplinas por meio de mecanismos de recompensa; promover um ambiente colaborativo para ampliar a capacidade criativa; a ação criativa do professor, planejando cuidadosamente as aulas e efetivamente orientando os estudantes; e humanizar os futuros publicitários, pois o conhecimento se torna significativo quando as estratégias de ensino incorporam o entorno ao cotidiano universitário.

\section{REFERÊNCIAS BIBLIOGRÁFICAS}

ALENCAR, Eunice M. L. Soriano de; FLEITH, Denise de Souza. Inventário de práticas docentes que favorecem a criatividade no Ensino Superior. Psicologia: Reflexão e Crítica, v. 17, n. 1, p. 105-110, 2004.

ANASTASIOU, Léa. Construindo a docência no ensino superior. In: ROSA, Dalva; SOUZA, Vanilton (org.). Didática e práticas de ensino. Rio de Janeiro: DP\&A, 2002.

ANASTASIOU, Léa. Ensinar, aprender, apreender e processos de ensinagem. In: ANASTASIOU, Léa; ALVES, Leonir (org.). Processos de ensinagem na universidade: pressupostos para as estratégias de trabalho em aula. Joinville: Univille, 2006.

CASTANHO, Maria Eugênia. A criatividade na sala de aula universitária. In: VEIGA, Ilma; CASTANHO, Maria Eugênia (org.). Pedagogia universitária: a aula em foco. São Paulo: Papirus, 2000.

CHAMBERS, Jonathan. College teachers: their effect on creativity of students. Journal of Educational Psychology, v. 65, n. 3, p. 326-334, 1973.

LUPTON, Ellen; PHILLIPS, Jennifer. Novos fundamentos do design. São Paulo: Cosac Naify, 2008.

MARTÍN-BARBERO, Jesús. A comunicação na educação. São Paulo: Contexto. 2014.

MITJÁNS MARTÍNEZ, Albertina. A criatividade na escola: três direções de trabalho. Linhas Críticas, Brasília, v. 8, n. 15, p. 189-206, 2002.

MOREIRA, Marco Antonio. Abandono da narrativa, ensino centrado no aluno e aprender a aprender criticamente. In: VI ENCONTRO INTERNACIONAL E III ENCONTRO NACIONAL DE APRENDIZAGEM SIGNIFICATIVA. Anais..., São Paulo, 2010. 
comunicação \& educação • Ano XXV • número 1 • jan/jun 2020

NÓVOA, Antonio. Vidas de professores. Porto: Porto, 1992.

OROZCO GÓMEZ, Guillermo. Educomunicação: recepção midiática, aprendizagens e cidadania. São Paulo: Paulinas, 2014.

PIRATININGA, Luiz Celso de. Publicidade: arte ou artifício. São Paulo: T.A. Queiroz, 1994.

RODARI, Gianni. Gramática da fantasia. São Paulo: Summus, 1982.

SANTROCK, John. Psicologia educacional. Porto Alegre: AMGH, 2009.

STENBERG, Robert, LUBART, Todd. The concept of creativity: prospects and paradigms. In: STERNBERG, Robert; LUBART, Todd (org.). Handbook of creativity. Londres: Cambridge University Press, 1999.

SODRÉ, Muniz. Reinventando a educação: diversidade, descolonização e redes. Petrópolis: Vozes, 2012.

WEINER, Rui. A criatividade no ensino do design. Dissertação (Mestrado) - Universidade das Belas Artes, Universidade do Porto, 2010. 